\title{
AANTEEKENINGEN OP HAMELBERGS WERKEN
}

DOOR

W. R. MENKMAN

II

Engel Raapzaadt, een Statiaan, die in 1749 in het huwelijk trad (Jaarv. VI, Genealogie) is allicht de man dien wij later aantreffen als schipper op de bark Rachel 1 ).

De Heer Raey (Ned. I., D. 32, 42) was volgens De Laet de hoofdparticipant-bewindhebber van Amsterdam Jehan Raye 2).

Abraham Ravené en zijn zoon Andries (Jaarv. VI, Genealogie), beiden Statianen, zullen wij terugvinden bij het garnizoen van het eiland, de eerste als commandant, de tweede in een ondergeschikten rang ${ }^{3}$ ).

De Heer Reael (Ned. I, 42) komt ook bij De Laet voor, als Amsterdamsch bewindhebber, met den voornaam Reynier 4).

Aan Jan Erasmus Reining (Ned. I, 54, 76, D. 122, 126; Ned. II, $40,56,57$; Jaarv. III) is ook door anderen dan H. de noodige eer bewezen; hij heeft geen groote rol gespeeld in de geschiedenis van ons zeewezen in het algemeen, maar verdient wel een eereplaats in die van de Ned. Antillen s), naast andere Zeeuwsche vrijbuiters.

De Van Rhee's (Ned. II, 12, 18, 42, D. 19) zijn behalve in die van de Bovenwindsche eilanden, ook bekend in de geschiedenis van Berbice, waar zij, reeds in 1624, tezamen met de Van Pere's, een kleine vestiging hadden, welke hun de ruilproducten der Indianen, anotto, verfhout enz., leverde 6). De „Duitsche” inwoners

1) W. I. Gids, XIV, 379.

2) Iaerl. Verh., 33.

3) W. I. Gids, XV, 24, 113, 325; Knappert, Gesch. Ned. Bovenw. Eil., zie vroeger.

4) Iaerl. Verh., 32.

s) P. de la Ruë, Staatk. en Heldhaftig Zeeland, Middelburg 1736; Eugène Sue, Hist. de la Marine française, III, Paris 1845; Zeer Aenm. Reysen, zie vroeger.

6) Harlow, Colon. expeditions, par. V, No. 1, Descr. of Guyana, zie vroeger. 
van Sint Eustatius, die in 1673 wegens hun déloyaal gedrag door den krijgsraad van het Zeeuwsch-Hollandsche eskader ,,geëxamineerd" werden, verontschuldigden zich o.a. met de bewering dat „,de Heer van Ree", hun patroon, hen niet, zooals beloofd was, geholpen had aan de middelen om het eiland te verdedigen; de kooplieden-kolonisatoren, patroons of compagnieën, bleven in den regel in gebreke op het punt van de defensie, welke natuurlijk groote uitgaven vereischt zou hebben 1).

Balthazardu (de) Rieu (de Rue) komt, behalve in de Curaçaosche geschiedenis (Ned. I, 87 D. 93; Ned. II, D. 38) als inwoner van het eiland, plantagehouder en reeder aldaar, ook voor als koopman te Amsterdam, betrokken bij den slavenhandel 2).

$H$. noemt, in verband met den slavenopstand op Curaçao van 1795, den Franschen generaal Rigaud, van Saint Domingue (Jaarv. III, 121); een dertigtal jaren later leefde op Bonaire een oude Franschman, uit Toulouse afkomstig ${ }^{3}$ ), eveneens Rigaud geheeten, van wien Mr. B. de Gaay Fortman, gevonden heeft dat hij in 1834, 71 jaar oud, overleed 4).

Benoît-Joseph Rigaud, de mulatten-generaal van Saint Domingue, werd in 1761 in het stadje Aux Cayes (Zuidwestkust) geboren en overleed in 1811; hij heeft een groote rol gespeeld in de geschiedenis der revolutie op het eiland, der Engelsche interventie aldaar, van de pogingen van Bonaparte om de kolonie te herstellen en der instelling van een nationaal bewind s). Hoeveel prestige een kleurling-generaal bij de slaven in andere koloniën kon hebben blijkt wel hieruit, dat Toela, een der aanstichters van den opstand op Curaçao van 1795, zich Toela-Rigaud noemde (Jaarv. III, 138).

Francisco de Rivas (Jaarv. III, 90), die de reis met het slavenschip De Koning Balthazar medemaakte, moet geweest zijn Dr. Francisco de Ribas, die te Cadix als huisprelaat bij Balthazar Coymans geleefd had, welke laatste in Spanje een zekeren schijn van Katholiciteit ophield; Don Balthazar had als ketter steeds de te-

1) De Zeeuwsche expeditie, zie vroeger.

$\left.{ }^{2}\right)$ Doc. ..Slave Trade...., I, sevent. cent., doc. Nos 76, 79, 89, zie vroeger.

3) G. B. Bosch, Reizen in West-Indië, II, Utrecht 1836.

4) Koloniaal Weekblad (orgaan van de Vereeniging Oost en West), 7 Jan. 1926.

s) P. Larousse, Gr. dict. univ.; H. P. Davis, Black Democracy, The story of Hayti, London 1929. 
genwerking te vreezen der geestelijkheid, die ook ,,in zaken" veel invloed had 1 ).

Dat Ds. Charles de Rochefort (Ned. II, D. 29; Jaarv. IV, Tobago), de Waalsche predikant, die op Tortuga gediend heeft, Tobago beschreven en later te Vlissingen en te Rotterdam gestaan heeft, ook Curaçao bezocht (in 1649), weten wij door de onderzoekingen van Prof. Knappert 2).

Aangaande de Roeberge's (Ned. I, 38, 71, D. 48, 49) had H. ook bij De Laet iets kunnen vinden. Ik heb indertijd trachten te verzamelen wat er aangaande deze Zeeuwsche kooplieden, kaapvaartreeders en kolonisten te vinden is ${ }^{3}$ ).

De naam van den Hagenaar Daniël Arents van Roermond, die in 1715 op Curaçao in het huwelijk trad (Jaarv. V, Trouwboek Curaçao 1714/1722) lijkt op dien van de Van Romondts en ook de voornaam Arent is in het laatstgenoemde geslacht voorgekomen. De stamvader echter der Westindische Van Romondts was Diederik Johannes, de zoon van een Amsterdamschen makelaar, die van 1820 tot 1840 gezaghebber was van Sint Maarten en Saba, overleden op eerstgenoemd eiland in 1849. In Nederland was de naam oorspronkelijk Van Romunde 4 ).

Natuurlijk had Jean Baptiste Du Tertre gelijk, toen hij tegensprak dat De Ruyter (Ned. II, 13, 15, 20, 21, 22, 23, 39, D. 24, 29, 36; Jaarv. II, 111, 112) eenig ander aandeel in de bezitneming van Sint Maarten (1648) gehad zou kunnen hebben, dan dat hij met zijn schip de expeditie van Sint Eustatius er heen bracht. De Ruyter was destijds weder schipper ter koopvaardij en handelaar, een particulier persoon dus; toch is ook later nog wel aangenomen, men zou zeggen ten onrechte, dat hij het eiland ,,voor de Staten" in bezit nam s). De commissie van Abraham Adriaensz. aan Martin Thomas van 14 Februari 1648, door Du Tertre gegeven, zei duidelijk dat Sint Maarten gekoloniseerd zou worden ten bate van Heeren Meesters en Patroons van Sint Eustatius en de commandeur van laatstgenoemd eiland was wel, De Ruyter niet, een vertegenwoordiger van Staten en Compagnie, alsmede een mandataris van de patroons.

1) Irene A. Wright, The Coymans asiento, zie vroeger.

$\left.{ }^{2}\right)$ F. Nagtglas, Levensberichten van Zeeuwen, Middelburg 1890/

1893; Gedenkboek Ned.-Curaçao, 37, zie vroeger.

s) W. I. Gids, XVII, 200, XVIII, 168, 253, XX, 208.

4) J. C. Waymouth, Memories of Sint Martin, Neth. part, 1852/1926; Nederlands Patriciaat.

s) P. J. Blok, Michiel Adriaansz. de Ruyter, 's Gravenhage 1928. 
H. zegt dat Lucas Schorer (Ned. II, 43/54, D. 46, 47, 50), die in 1686 tot commandeur van Sint Eustatius benoemd werd, een oudbewindhebber van Kamer Zeeland was; Prof. Knappert spreekt van Lucas Schorer, vice commandeur van Saba, met wien het slecht afliep. Knappert kent ook een Zeeuwschen predikant van denzelfden geslachtsnaam 1).

Uit gegevens welke de redactie van dit tijdschrift van een medewerker mocht ontvangen, valt af te leiden dat wij met een en denzelfden persoon te doen hebben, hoewel het onduidelijk blijft waarom de man die zich eerst zoo verdienstelijk gemaakt had, zich later met de functie van vice commandeur van Saba moest vergenoegen; $H$. vermeldt ongenoegen van Schorer met de bewoners van Saba (Ned. II, 44), maar dat heldert ook de zaak niet op.

Lucas Schorer dan werd in 1657 te Middelburg geboren, als zoon van Daniël S. en Maria Backer, zijn broeder in Zeeland was Steven Schorer; een geschilderd portret van Lucas is in het bezit van particulieren h. t. l. (niet in de Iconographia Batava van E. W. Moes). Volgens een brief van 20 Juli 1698 van Saba, aan de West-Indische Compagnie, was hem (Lucas Schorer) „niemant hier vermaagtschap"; hij stierf ongehuwd.

Joh. Salomonsz., commandeur van Sint Eustatius, schreef 3 Juli 1696 aan Bewindhebbers te Middelburg, dat hij drie gecommitteerden uit den Statiaanschen Raad naar Saba gezonden had ,ten eijnde sijn persoon (Lucas Schorer) te demitteren en meteenen een capabel persoon in sijn plaets tot commandr aldaer te stellen, waertoe ons wesende voorgedragen den persoon van $\mathrm{S}^{r}$ Adriaen Runnels d'jonge enz." H. vermeldt (Ned. II, 54), dat de in 1696 tot commandeur van Sint Eustatius gekozen Johannes Salomonsz. tot vice commandeur van Saba aanstelde Adriaan Runnels Jr.

Het bovenstaande mede ter aanvulling van de Encyclopedie van Ned. West-Indië (bl. 329), welke onder de Kommandeurs, gouverneurs en gezaghebbers der Bovenwindsche Eilanden (1636 -1845) vermeldt Lucas Schorer 1686-1689.

Schoute $(n)$; deze naam komt in H's naamregister voor: D. 28, 167; wij vinden echter in Ned. I, Documenten, Hendrik Schoute op pagina 128.

Frans Sejourne, kaperkapitein van Curaçao in 1782 (Ned. I, 180) droeg denzelfden naam als de inwoner van Sint Eustatius die in 1766 zijn huis illumineerde ter gelegenheid van de aanvaarding

1) Gesch. Ned. Bovenw. Eil., zie vroeger. 
van het erfstad houderschap door Prins Willem V 1). Verder was er in de tweede helft van de achttiende eeuw nog een eigenaar van plantages in Berbice genaamd C. F. Séjourné 2).

Joannes van Selm (Ned. I, 205, D. 186) was niet de schrijver, doch de uitgever van de Beschrijving van het eiland Curaçao van 1779.

De Heer (van) Serooskercke (Ned. I, D. 17, 42, 43) was Pauwels Serooskercke, door De Laet genoemd als bewindhebber in de Kamer van Zeeland ${ }^{3}$ ).

De Heer van Setterich (Ned. I, D. 37) komt bij De Laet voor als Nicolaes van Sitterich, bewindhebber Kamer Amsterdam 4).

Jan Sijmonsen (de Buck), die vóór Juni 1673 vice commandeur van Sint Maarten geweest was en op Sint Eustatius vermoord werd, wordt door $\mathrm{H}$. niet genoemd s).

Ook de naam Snouck (Ned. I., 72; Ned. II, 10, 11, D. 13, 17, 18) komt reeds vroeg voor in de geschiedenis onzer commercieele expansie. Dirck Reynersz. Snoeck, geboortig van Enkhuizen en wonende te Medemblik, was in 1600 op reis gegaan met een Emdensch schip naar Pernambuco, om te handelen 6). In het Rijksmuseum te Amsterdam bevindt zich een portret van Jan Pietersz. Snoeck, begin zeventiende eeuw.

A. Sorgeloos was een ingezetene van Sint Eustatius in 1687/1688 (Ned. II, D. 48); een Ariaen S. was raadslid van het eiland in 1688, (Jaarv. IV, Extract uyt de Boecken van d.Hr Lowijs houtcooper Zal.) en een Adrian S. teekende in 1686 een verklaring betreffende een geval van zeeroof op Tortola 7).

Er komen bij $\mathrm{H}$. verschillende personen voor met den naam Speght of Specht (Ned. I., 60, 95, 223, 225, D. 106, 119, 167, 185). Ook Knappert wijst op de familiebetrekkingen tusschen de Donckers en de Spechts en vindt het moeilijk aan te nemen dat Ds. Philippus Specht in zijn huis een tapperij hield ${ }^{8}$ ). Zie verder onder Commandeurs Aruba.

$\left.{ }^{1}\right)$ Maand. Nederl. Mercurius, 1766.

2) Kortbondige beschrijvinge van de colonie de Berbice, Amsterdam 1763.

s) Iaerl. Verh., 35

4) Iaerl. Verh., 33.

s) De Zeeuwsche expeditie naar de West, zie vroeger.

6) Häpke, Akten, zie vroeger.

7) Calendar of State Papers, Am. \& W. I., 1685/1688, No. 678, III ; zie ook W. I. Gids, XX, 186.

8) Gedenkb. Nederland-Curaçao, 42, 47, zie vroeger. 
H. citeert den Holl. Mercurius, van 1677 (Jaarv. IV, 27) en ook eenige Fransche werken ter zake van de verdediging van Cayenne door Sprenger; Jhr. van Panhuys had er dus niet aan behoeven te twijfelen of zijn Quijrijn Spranger werkelijk de man was die in 1676 in Fransche krijgsgevangenschap geraakt was en voor wien Joan Maurits van Nassau een goed woordje deed bij D’Estrades 1). Iets anders is of deze Spranger dezelfde was als de commandeur van dien naam die al eens eerder (op 15 Mei 1664) dezelfde kolonie aan de Franschen had moeten overgeven. Doch ook deze vraag schijnt bevestigend beantwoord te moeten worden; immers $Q$. Spranger was betrokken bij het kolonisatieplan van 1659, Du Tertre noemt Guirin Spranger een uit Brazilië uitgeweken Nederlander en roemt hem wegens zijn gedrag bij de capitulatie van $1664{ }^{2}$ ).

Sir William Stapleton (Ned. I, 56; Ned. II, 17, 25, 37, 39/43; Jaarv. II, 125) noemt $H$. nu eens de gouverneur der Engelsche benedenwindsche eilanden, dan weder de gouverneur van Nevis. De Leeward Islands vormden (en vormen nog) een federatie; het eiland waar de gouverneur resideert wordt rechtstreeks door hem bestuurd, terwijl ieder der andere een raad heeft, met een president als hoogste plaatselijke autoriteit. Volgens Hugh Edw. Egerton was Stapleton een ,,very competent governor"; hij en zijn collegas werden belemmerd in hun pogingen om de Westindische eilanden tot bloei te brengen door de navigation laws ${ }^{3}$ ).

Van Pieter Stuyvesant, toch wel de belangrijkste figuur in de geschiedenis der Nederlandsche Antillen, vertelt $\mathrm{H}$. eigenlijk niet zoo heel veel (Ned. I, 38/44, 95, 221, 223, D. 51, 52, 54, 55, 57, 58, 69, 70, 89, 184; Ned. II, 13; Jaarv. II, 111, 112; Jaarv. IV, 135). Afkomst en familierelaties (S. was de zoon en de schoonzoon van predikanten), aanvankelijke loopbaan (militaire dienst in en buiten Nederland) en eerste functie bij de West-Indische Compagnie (De Laet spreekt niet over Stuyvesant) worden niet vermeld 4). Was S. een zeeman of een landmilitair? Dat hij in 1635 supercargo in Brazilië geweest zou zijn, is niet direct begrijpelijk; de voor $\mathrm{Cu}$ raçao in 1645 ontworpen sterktestaat echter geeft ,,1 supercargo vant magazijn" (Ned. I, D. 59), dus supercargo was niet steeds een maritieme betrekking. Intusschen is het mogelijk dat de Braziliaansche supercargo niet Stuyvesant was (zie Tolck). $\mathrm{H}$. is er niet zeker van of S. inderdaad betrokken geweest is bij de poging

$\left.{ }^{1}\right)$ W. I. Gids, XII, 540

$\left.{ }^{2}\right)$ Hist. gener. des Antilles, tome III, traité I, zie vroeger.

3) A short history of British Colonial Policy, 1606-1909, London, 1932.

4) Dictionary of American Biographie, XVIII. 
tot herneming van Sint Maarten in 1644; de sedert gepubliceerde Spaansche documenten echter laten geen twijfel over of hij heeft inderdaad de expeditie in kwestie aangevoerd en in den strijd een been verloren 1). Bij den mislukten aanslag der Spanjaarden op Curaçao van 1642 en de daarop gevolgde représailles der onzen, leeren wij S. kennen als krijgsoverste ${ }^{2}$ ).

Uit Stuyvesants brieven is wel afgeleid dat hij een geletterde was ${ }^{3}$ ); de gezagdragers echter zullen wel weinig zelf geschreven hebben en zij hadden in den regel wel een Latinist (de secretaris, of anders de predikant) in de nabijheid. Aanvankelijk bediende S. zich tegenover den vijand van het Latijn, wat zelfs de ruwe Scheveninger Houtebeen eveneens deed; S. wist spoedig de noodzakelijke briefwisseling in het Spaansch te doen voeren 4).

Als directeur generaal in Nieuw Nederland heeft S. nog eenmaal de West bezocht, in 1654, toen alleen op Barbados acht Nederlandsche schepen krachtens de navigation law in beslag genomen waren. Een der door Cromwell benoemde commissarissen" for the management and government of the West Indies" schreef dat ,this man's business was to settle a faire trade between the Netherlands and this place; but we spoiled the sport". Men hield op Barbados S. scherp in het oog, want: ,we are in more feare of him for discovering our raw and defective forces, than all the world besides" s).

Van Stuyvesants correspondentie met den Curaçaoschen vice directeur Matthias Beck is veel bewaard gebleven; de directeur generaal liet van Curaçao slaven komen, als bedienden voor hem zelf en voor de andere ambtenaren der Compagnie, alsmede voor de werkzaamheden te Nieuw Amsterdam. Op 17 Februari 1660 schreef S. dat hij niet zelfzuchtig wilde schijnen en natuurlijk voor de slaven den prijs wilde betalen welke op Curaçao (bij verkoop aan de Spanjaarden) gemaakt kon worden, maar hij meende toch dat Christenen en Compagnies dienaren voorrang behoorden te genieten boven Spanjaarden en ongeloovige Joden s), wat er op wijst dat de aanvoer van negers beneden de vraag bleef en Beck

1) W. I. Gids, XVIII, 174

2) W. I. Gids, XVIII, 171, 173.

3) Ruth Putnam, The Dutch element in the United States (Bijdr. Vad. Gesch. \& Oudheidk., IV, 9).

4) W. I. Gids, XVII, 165, 167.

s) E. B. O'Callaghan, History of New Netherland or New York under the Dutch, II, 285, New York 1855.

6) Doc. .. Slave Trade...., Vol. III, doc. No. 328, zie vroeger. 
alles deed om den handel met de Spaansche koloniën te bevorderen. Stuyvesant had op Curaçao een ,,koraal” gehad en ook een aantal (vermoedelijk zwarte) slaven; Beck was belast met de liquidatie van dit bezit. Op 15 November 1664 maakte de vice directeur zijn excuses voor de grove fout welke indertijd gemaakt was door Stuyvesants slaven te verkoopen naar de Spaansche koloniën, waaronder nog wel kleine kinderen, door de zorgen van Mevrouw S. (een dominees dochter) gedoopt 1).

Over de betrekkingen welke Stuyvesant reeds in zijn Curaçaoschen tijd met Nieuw Nederland onderhouden had, schrijft ook H., o.a. over het doorzenden van een schip met vluchtelingen en militairen uit Maranham naar de Noordamerikaansche kolonie, in $1644^{2}$ ).

De geschiedenis van S. als magistraat en hervormer in het Europeesche kolonisatiegebied aan de Hudson-rivier, van zijn strijd met de Indianen, de Zweden en de Engelschen en zijn overgave van Nieuw Nederland in den tweeden Engelschen oorlog, valt buiten ons bestek. Amerikaansche historici zijn verdeeld in hun oordeel over hem; sommige noemen hem een koppig en bekrompen dwingeland, andere verheffen hem tot een modernen Romulus, ,, a just man and a determined man ${ }^{3}$ )." Onze eigen litteratuur gewaagt van zijn moeilijkheden met de patroons en de kolonisten van Nieuw Nederland en van zijn tekort aan verdraagzaamheid tegenover anders denkende Protestanten en tegenover Joden.

Van de andere dragers van den naam Stuyvesant noemt H. alleen den luitenant ter zee van het eskader Van Bylandt in 1778, vermoedelijk dezelfde die aan boord van de groote Mars diende, 4 Febr. 1781 door de Engelschen in de nabijheid van Sint Eustatius genomen 4). Knappert heeft nog een Judith Stuyvesant gevonden op Sint Eustatius, op het eind der zeventiende eeuw s). Er leefde echter tegelijk met Pieter ook een Hendrick Janssen Stuyvesant, een schipper in de vaart tusschen Nieuw Nederland en Curaçao $\left.{ }^{6}\right)$.

1) E. B. O'Callaghan, Voyages of the Slavers St. John and Arms of Amsterdam, Albany 1867, corr. Stuyvesant-Beck 1660-1664.

2) W. I. Gids, XVIII, 175.

3) Th. A. Janvier, The Dutch founding of New York, 1903; James Grant Wilson, The Memorial History of the city of New York, N. Y. 1892.

4) C. de Jong, Reize, zie vroeger.

s) Gesch. Ned. Bovenw. Eil., zie vroeger.

6) O'Callaghan, Voy. of the Slavers, zie vroeger. 
Van de Thijssens die H. noemt (Ned. I, 20, D. 68) was Marten de latere $Z$ weedsche admiraal Anckarhjeld 1).

Jacob Pietersz. Tolck (Ned. I, 38, 221, D. 46) werd in Spaansche documenten van 1639 genoemd als de nieuwe gouverneur van $\mathrm{Cu}-$ raçao, wat eenigszins de leemte aanvult welke $\mathrm{H}$. na Van Walbeeck heeft moeten laten bestaan. Hoe lang het bestuur van Tolck geduurd heeft, die reeds in 1641 alweder deel nam aan den tocht van De Ruyter om onze bondgenooten, de Portugeezen, te ondersteunen, laat zich niet met juistheid vaststellen. De Laet noemt Tolck als equipagemeester in Brazilië in 1635, wat H. misschien niet opgemerkt heeft ${ }^{2}$ ). Het is mogelijk dat de Amerikaansche biograaf van Stuyvesant (zie vroeger) zich vergist heeft tusschen dezen laatste en Tolck, wat de gelijkheid van jaartal doet vermoeden.

Tribier (Ned. I, 83, D. 90, 118, 129, 168); deze naam komt op p. 83 van het eerste deel niet voor.

De commandeur Maarten Valck (Ned. I., D. 16) wordt ook door De Laet bevelhebber genoemd van een deel der vloot onder Hendrick Loncq, in 1629 naar Brazilië $\left.{ }^{3}\right)$. Zie Van Walbeeck.

Wij vinden een Vignon als secretaris van Sint Eustatius (Ned. II, 46), een Nicolaas Vignon, eveneens secretaris van het eiland (Ned. II, D. 48) en dan wederom een Nicolaas V. in dezelfde functie (Jaarv. III, Extract uyt de Boecken van d. $\mathrm{H}^{\mathrm{r}}$ Lowijs houtcooper Zal.), alles ongetwijfeld dezelfde persoon. De naam Heldewier Vignon, ontstaan na het huwelijk van Jean Guillaume Heldewier en Sybille Vignon, in het laatst der achttiende eeuw, komt, evenals ieder der afzonderlijke namen, in onze Westindische geschiedenis voor; Heldewier Vignons hebben op Curaçao en in Suriname geleefd 4 ).

De Vogelaer (Ned. I., D. 45) was de Amsterdamsche bewindhebber Marcus de Vogelaer, voorkomende bij De Laet s). Een veertigtal jaren later (1673) vinden wij een Abraham de Vogelaer als koopman te Fayal (Azoren) 6).

Ds. Wilhelmus Volckringh (Ned. I., 95) deed volgens Knappert in 1664 zijn intrede op Curaçao 7).

1) Kernkamp, Zweedsche Archivalia, zie vroeger.

2) W. I. Gids, XVII, 202, XVIII, 177, XX, 207.

3) Iaerl. Verh., 174.

4) Nederl. Patriciaat.

s) Iaerl. Verh., 33.

6) De Zeeuwsche expeditie naar de West, zie vroeger.

7) Gedenkb. Ned.-Curaçao, 40, zie vroeger. 
Van de door H. genoemde De Vriesen (Ned. I, D. 42, 123) was de eerste de Amsterdamsche schepen en bewindhebber der Compagnie Jan Gijsbertsz. de Vries, bij De Laet 1).

Een Willem Lievensz. van Vrijberge (Ned. II, D. 38) komt bij Nagtglas voor (1624-1679), maar van eenige relatie met de WestIndische Compagnie wordt niet gesproken 2 ).

Van Johannes van Walbeeck (Ned. I, 21/23, 25, 27, 28, 30/33, 37, 221 , D. 15/17, 23/25, 32/35, 37, 41, 44, 45, 47) geeft $H$. niet alle levensbijzonderheden welke bekend waren, toch reeds niet vele. Zoo vertelt hij b.v. niet dat Van W. te Leiden gestudeerd had (zie den Leidschen studentenalmanak), dat hij de reis met de Nassausche vloot en een reis naar Indië had medegemaakt en Laurens Reael had vergezeld naar Denemarken ${ }^{3}$ ).

Dat Van W. met Loncq naar Brazilië zou gegaan zijn als vice commandeur der soldaten, is natuurlijk foutief; De Laet zegt dat hij vice-Commandeur was onder Valck (zie bij dezen), d.w.z. dus onderbevelhebber van de vlootafdeeling waarover Valck het bevel voerde 4). Van W. was geen militair van beroep; ook heeft hij ten slotte den tocht in kwestie niet medegemaakt, immers hij kwam 20 April 1630 te Pernambuco aan, als zelfstandig commandeur van twee schepen, direct uit Patria, hebbende aan boord 70 soldaten 5 ).

Hendrick Brouwer, de oud-gouverneur generaal van Indië en bewindhebber der West-Indische Compagnie, die in 1642/1643 een expeditie leidde naar de westkust van Amerika, schreef: „,De Heer Walbeeck, in dye quartieren gereist hebbende", wat wel zal hebben gezien op den tocht der Nassausche vloot van een twintigtal jaren eerder, toen Van Walbeeck, door zijn opleiding een mathematicus, een kaart gemaakt had van het Zuiden van Vuurland 6).

De man die Sint Kitts gekoloniseerd heeft was Thomas (sedert 1629 Sir Th.) Warner, niet Charles Warner (Ned. II, 8, 12, D. 25; Jaarv. II, 108). Hij was de eerste gouverneur van het Engelsche deel van Sint Christoffel, in 1636 bekleed met den rang van luitenant generaal over alle eilanden van het Carlisle-charter 7).

1) Iaerl. Verh., 32.

2) Levensberichten II, zie vroeger.

3) Van Wassenaer, Historisch Verhael, XIV, 52.

4) Iaerl. Verh., 174.

s) Iaerl. Verh., 195.

6) Mr. A. Telting, De Nederlanders in Chili 1643 (Indische Gids 1913);

Journael Nassausche vloot, bij Gilles Joosten Saeghmans.

7) Williamson, The Caribbees, zie vroeger. 
Misschien is $\mathrm{H}$. den voornaam Charles tegengekomen als dien van den buitenechtelijken zoon van Thomas W.; de avontuurlijke geschiedenis van dezen halfbloed - zijn moeder was een Indiaansche van Dominica - is op verschillende plaatsen beschreven 1). Verbintenissen met Indiaansche vrouwen behoorden nogal eens tot de inboorlingenpolitiek; de onzen hadden daarmede reeds vroegtijdig succes, waarvan de geschiedenis van Aert Adriaensz. van Groenewegen (van Scherpenisse) in Essequibo getuigt. Deze geschiedenis valt buiten ons bestek, maar $\mathrm{H}$. heeft toevallig aanleiding gehad dezen Adriaensz. te noemen (Ned. II, D. 21); zijn morganatische zoon Amos heeft later den vader opgevolgd en wordt wel eens met dezen laatste verward 2).

Als opvolger van Le Grand op Curaçao noemt H. David Adam Wilschut (Ned. I, 37, D. 43, 44, 46); hij moet de kapitein Wilschut (Wildschut, Wildtschut) zijn, door De Laet genoemd onder de officieren die in 1633 en 1634 in Brazilië dienden $\left.{ }^{3}\right)$.

De naam De Windt (De Wint) komt bij $\mathrm{H}$. reeds in de tweede helft der zeventiende eeuw op de Bovenwindsche Eilanden voor (Ned. II, D. 40, 44, 48); Knappert vertelt dat Jan de Windt, de vice commandeur van Sint Maarten van 1718, een Middelburger was van goede familie, die als schoolmeester was uitgezonden 4 ).

Dat Jan de Yllan (Ylam), Curaçaosch landeigenaar van 1651 (Ned. I, D. 89), een der eerste Joodsche kolonisten geweest is (João Ilhão), schijnt aan H. ontgaan te zijn s).

Gouverneurs va n $\mathrm{Cur}$ a ça o. In de door $\mathrm{H}$. gegeven lijst (Ned. I., 221/222) kunnen enkele correcties worden aangebracht.

Wie de directe opvolger van Van Walbeeck geweest is blijft onbekend; na zijn vertrek in 1636 vinden wij Tolck in 1638 of 1639 (zie hiervoor).

Tusschen Tolck en Stuyvesant moet er wederom een interimaat geweest zijn, maar dit was van zeer korten duur, want laatstge-

1) William Dampier, New voyage around the world, London 1927; Du Tertre, Hist. gener., tome III, traité II, chap. II, par. 1, zie vroeger.

2) Newton, Eur. nations, zie vroeger; Gedenkb. Ned.-Cur., 99 zie vroeger.

3) Iaerl. Ver., 326, 345, 380, 398.

4 ) Gesch. Ned. Bovenw. Eil., zie vroeger.

s) Gedenkb., zie hooger. 
noemde was reeds in het najaar van 1642 op Curaçao ${ }^{1}$ ) en trad niet zooals $\mathrm{H}$. meende in 1643 in functie.

Van Campen, aan wien in April 1635 vergund werd naar $\mathrm{Cu}-$ raçao te gaan, die 27 Juli van dat jaar aldaar aanwezig was en die 3 Maart 1642 directeur van Curaçao genoemd werd, kan zoowel de eene als de andere gaping aangevuld hebben.

Matthias Beck was inderdaad vóór 1659 en wel in 1657, vice directeur; er berust immers in een der Amerikaansche archieven een brief van hem aan de Kamer Amsterdam, gedagteekend 11 Juli van laatstgenoemd jaar 2).

Van Berlicum overleed 29 December 1669 en Wilhelm Beck zal hem wel direct (tijdelijk) hebben vervangen ${ }^{3}$ ).

Predik a n t e n o p C u r a ça o. H.'s lijst (Ned. I., 223, 224) kan, aan de hand van Knapperts mededeelingen, aangevuld worden als volgt:

na Fredericus Vitteüs vinden wij Jonas Aertsz. (1640 - ? ); Joh. Corn. Backer was reeds in 1642 in functie; na hem het interimaat van Joh. Walrave (den ziekentrooster) van 1647 tot ?; Van Beaumont volgt hem in 1659 op (niet 1668); na Van B. vinden wij Christiaen Coningsvelt, niet door H. genoemd; dan Wilhelmus Volckring 1664-?; tusschen Specht en Verkuyl komt nog Theo van Dobben (?), 1677-1678(?); Ferrarius trad eerst in 1727 op, niet 1726; Erichson in 1729, niet 17284).

Com m a n d e urs A r u ba. Volgens Bosch zou eerst in het begin der achttiende eeuw de Nederlandsche vlag op Aruba geplant zijn, doch $\mathrm{H}$. heeft voor het eerst in 1680 iets gevonden over een commandeur van dit eiland (Ned. I, 117, 225); de boekaniers evenwel die Aruba in 1669 bezochten vonden er reeds een onderofficier als gezaghebber ${ }^{5}$ ). Eenige jaren eerder nog komt een Ier als commandeur voor, die echter Wilhelm heette 6$) ; \mathrm{H}$. noemt hem natuurlijk niet, maar evenmin den burgercommandeur Pieter (de) Boer, die in 1740 opgetreden en later vermoord zou zijn, volgens Ds. Bosch, terwijl volgens den laatstgenoemden schrijver

1) W. I. Gids, XVIII, $171 / 173$.

2) Doc. .. Slave Trade...., I, sevent. cent., doc. No. 30, zie vroeger.

3) Gedenkb. Ned.-Cur., 43, zie vroeger.

4) Als boven, 34/53

s) Reizen in West-Indië, zie vroeger; W. I. Gids, XVII, 69.

6) Zeer Aenm. Reysen, 55, zie vroeger. 
Daniel Nieukerk nog in 1752 aan het bewind zou zijn geweest, wat niet klopt met het jaartal van den slavenopstand.

H. eindigt met den commandeur Borchard Specht (1792), die volgens Bosch ook al een slavenoproer medegemaakt zou hebben en opgevolgd zou zijn door zijn zoon Pieter 1). Een Pieter Specht komt ook bij H. voor (Ned. I, D. 167), in 1735 echter.

Bosch was nog te weten gekomen dat in de achttiende eeuw op Aruba een kapitein en een luitenant gevestigd waren, de eerste een blanke, de tweede een Caraib, onder welken laatste de Indianen en de vrije gekleurden stonden ${ }^{1}$ ).

C o m m and e urs B on a i r e Ook dit lijstje (Ned. I, 226) begint te laat; volgens de Spaansche documenten was er reeds onder Stuyvesant een gezagdrager op Bonaire gevestigd, wiens naam echter verloren geraakt is ${ }^{2}$ ).

Persoonsnamen Bovenwindsche Eilanden. H. laat zijn ,,Nederlanders op de West-Indische Eilanden II" plotseling eindigen en uit den aard der zaak is er op dit deel en de bijbehoorende documenten, dus geen inhoudsopgaaf.

Prof. Knappert ${ }^{3}$ ) heeft het werk voortgezet en geeft achterin zijn boek een register, van personen, plaatsen enz., alsmede lijsten van de commandeurs en patroons der verschillende eilanden, deze laatste lijsten compleet van den aanvang af. Om een aansluiting tot stand te brengen, heb ik een lijst samengesteld van de namen der personen in Hamelbergs tweede deel - en de bijbehoorende documenten - voorkomend; ik heb hetzelfde systeem gevolgd als $\mathrm{H}$. in zijn eerste deel, wat de cijfers betreft, maar tevens de voornamen opgenomen.

Deze lijst volgt hieronder:

1) Reizen in West-Indië, zie vroeger.

2) W. I. Gids, XVII, 173

3) Gesch. Ned. Bovenw. Eil., zie vroeger. 
Abrahamsen, Adriaen, D. 48

Adriaansen, Pieter, 24

Adriaansz., Hendrik, 22

Adriaensen, Jacob, D. 48, 50, 53

Adriaensen, Joris, 45

Adriaensz., Abraham, 12, 15, 17, D. 18,26

Adriaensz. v. Scherpenisse, Aert, D. 21

Adrichem, A. van, D. 19

Albemarle, Hertog van, D. 37

Andruson, 38

Arlington, Lord, 25, D. 37

Arnhem, G. van, D. 8, 9

Arnold, Jan, D. 48

Arthur, Jonathan, D. 48

Baerentsz. (Barens), Michiel (Machiel), D. 50, 53

Baerentsz., Willem, D. 53, 54, 55, 56

Bamfield, John, 23

Bane, Cornelis van, D. 51

Barre, De la, 27, 28, 30, 31, D. 39 , 43, 44

Batterie, Peter, 40

Baut, D., D. 19

Beck (Becx), Matthias, 28, D. 38

$\operatorname{Bee}(\mathrm{c}) \mathrm{k}, \mathrm{N}$. van, D. 57

Beel, Jonas, D. 48

Belain, zie Esnambuc

Benners, Joan (Joannes), 51, D. 48

Berens, Willem, D. 51

Bernardson, 23

Berre Sr., Willem, D. 50

Berre Jr., Willem, D. 50

Beverhou(d)t, Engelvan, 44, D. 48

Beverhoudt (Beverhout, Beverhoud), Lucas van, 57,58 , D. 48 , 52,53

Beuningen, Coenraad van, 34, 36

Binckes (Benckes), Jacob, 38, 39, 55,57

Blenac, Graaf de, 45, 47, 48, 49, D. 46,47

Block, Adriaan, 13

Blommaert, Samuel, 9, D. 12

Bogaert (Bogard, Boogard, Bogert), Gerrit (Garest, Gerret, Gerard, Gerart), 26, 28, 34, D. $40,42,44,46$
Bont, D. 18

Boudens, Victor, D. 6

Boudewijns, Bosman, D. 48

Braine, Edward, D. 40

Breton, Le, D. 47

Brewer, William, D. 40, 41, 42

Cahuzac, Sieur de, 10, D. 12, 13

Calwaert, Abraham, D. 48

Campen, van, zie Claessen

Carey, Theo., 23, 24, 25, D. 37

Carlisle, Hertog van, 9, 11, D. 8, 9

Carman, Abraham, D. 28

Chanca, Dr. Diego Alvarez, 5, D.3

Claessen, Jan, D. 9

Claesz. van Campen, zie Claessen

Claver, Reinier, 45

Cobham, Nathaniel, 23

Cock, Heynderyck de, D. 11

Codrington, Christ., 53, 54, D. 49

Coppin, David, D. 30, 32

Courpon, zie La Tour

Columbus, 5, D. 3

Crijnssen, Abraham, 38

Cubit, Joseph, 19

Cusac, zie Cahuzac

Cuvilje, Daniel, D. 50

Cuvelje, Guillaem, D. 48

Cuvelje, Jacob, D. 50

Cuvelje, Pieter, D. 48, 51

Cuvelje, zie Kuvillije

Davit, Jacques, D. 50

De la Tour, zie Tour

Demetrius, Cornelius, 42

De Pré, D. 45

De Rieu, zie Rieu

D'erville D. 39 , zie Dorvilliers

D'Estrades, 35, 36

Deucken, zie Duecken

Deucken, Jan, 48

Dinzey, Thomas, 50

Doncker, zie Sijmonssen

Donneau (?), $51,52,53$

Dorvilliers (D'orvilliers, Dornilie), 27, 31, D. 43 , zie D'erville

Ducq, zie Le Ducq

Duecken, Jan, 40, 44, zie Deucken

Du Tertre, 8, 9, 10, 13, 14, 26, 28, D. $6,24,30$

D'esnambuc, zie Esnambuc 
Edewards, Pieter, D. 48

Elbourcq (Elborgh), van der, D. 43,44

Esnambuc, Pierre Belain d', 8

Erville, zie D'erville

Esperance, Sieur de 1', zie Fond

Estrades, zie D'Estrades

Evertsen Schuttevaerder, Frans, D. 9

Evertsen de Jonge, Cornelis, 3839

Fack, Jan, D. 48

Fichot, 15, D. 24, 25, 26

Fokkes, Auske, 38

Fond, Bernard de la, D. 32

Fonteyne, Simon de, D. 48

Fosse, Edmondt (Edmond, Egmont) de (la), 17, D. 25

Fransen (de) Waterman, Cornelis, D. 21,22

Gardijn, Pierre, 11, D. 17

Garest, zie Bogaert

Garretson, Garret, 23

Gerritsz., Pieter, D. 23

Gijselingh, Johan, D. 20, 21

Gijssen, Jochem, 7, D. 10

Giron, 8

Grijpekoven, Johannis van, D. 48

Halman, Jasper, D. 50

Harman, John, 23

Hartman Jr, Isaac, D. 48

Hassel, John, 38

Hassilie, Richard, D. 51

Hay, James, zie Carlisle

Hazel, Joris, D, 48

Henderijck, Pieter, D. 51

Henderycks Jr, Guliaem, D. 51

Hendricx (Hendriks) Jr, Cornelis, D. 48,50

Hendriks Sr, Cornelis, D. 50

Heyden, van der, D. 20, 23

Heyliger, Gulliaem (Guliam), D. 48,51

Heyliger Jr, Guillaem, D. 48

Heyliger, Jan, D. 48, 50, 55, 56

Heyliger, Jannus, D. 48

Heyliger, Joannis, D. 53, 54, 55, 56

Heyn, zie Pietersz.
Hill, Richard, 52, D. 48

Hill, Ristier, D. 50

Hoen, 't, 21

Holleman, Jan, D. 48

Hoboken, Joannis van, D. 48

Holmes, Robert, 19, 20, 21, D. 36

Hoorn, Jan Jansz. van, zie Jans

Houtcooper, Louis, 43, 44, D. 48

Huygen, Lucas, D. 9

Iolly, Thomas, D. 6

Jacobsen, Lucas, 18, 37

Jacobsen, Wed. Wm Mussenden, D. 49

Jacobus, Hertog van York, 19

Jans (Jansz.) van Hoorn, Jan, 9, D. 10

Jansd., Coly, D. 9

Jansen, Hendrik, 52, D. 48

Janssen, Margieta, D. 38

Jeems, Jan, D. 48

Jeems Sr, Jan, D. 50

Jeems, Joris, D. 48, 53

Joachimy(i), (Albert), D. 8

Jobsen, Jan, D. 22

Johannissen, Boudewijn, 45, 46, D. 48

Jonge, Jhr. J. C. de, 20, 23, 38, 39, 55,56

Joppen, Jacobus, D. 44

Karel II, Koning van Engeland, 20

Kerckhove, Johannes van, D. 44

Kien, D. 17

Kien, Cornelis, 13, D. 23, 24

Kuvillije, Jan, D. 48, zie Cuvelje

Labat, Père, 50

Laet, Joannes de, 7

Lamont (Lamout), Isaac, 55, 58, D. 51,52

Lampsins, Adriaen, 13, 17, 55, D. $14,15,19,24,32,33,34,50$

Lampsins, Cornelis, 13, 17, 55, D. $14,15,19,32,33,34,50$

Langmeet, Jan, D. 48

Laurent, zie Saint Laurent

Le Breton, zie Breton

Le Ducq, Pieter, D. 48 
Le Ducq, Johannes, D. 48

Leendertsen, Cornelis, D. 22

Leon, de Saint, zie Sain(t) Leon

Leseur, Anthony, D. 48

Lespier, Pieter, D. 51

Lettré, 10, D. 13

Leverick, Willem, D. 48 , zie Leverock

Leverock, Jacobus, 58, zie Leverick

Leverock, Moses, D. 48, zie Leverick

Leyden, J. W. van der, D. 19

Lindesay, Jan, D. 50

Lindesaey, Joseph, D. 51

Longvilliers Poincy, Robert Chevalier de, 16, D. 27, 28, 29, 30, 32, zie Poincy

Longvilliers, Henry de, D. 30, 32, zie Poincy

Lordijck, Bartol, (Bartel), D. 48, 50

Lordijk, Emanuel, D. 48

Lordijk, Samuel, D. 51

Lucas, Abraham, D. 48

Lucas, Samuel, D. 6

Maecht, de D. 18

Malarba, Abraham, 23

Malet, Thomas, 55

Marceille, D. 44

Marcoe, Jan, D. 53, zie Markoe, Mercoe

Marcoe, Johannes Charles, D. 53, zie Markoe, Mercoe

Markoe, Pieter, D. 50

Martin, Sieur de Saint, 16, D. 26

Masuer, Johannes, D. 40, 43

Matissen, Hui, D. 50

Maxvelt, Jan, D. 22

Maynie, de, 56

Mercier, F, (T), 52, D. 48

Mercoe, Wed., zie Willemsd., zie Marcoe, Markoe

Merle, de, D. 28

Meppel (Meppelen) (van), 21, D. 37

Meurs, Jacob, D. 50

Meyer, Johannes, 58

Moddifort, zie Sijmons

Moddyford, zie Sijmons
Montfort, Jan Boucheron de, D. 48

Moor(e), Robbert, D. 48

Morgan, Edward, 23, 24

Morgan, Henry, 40

Morgan, Thomas, 25

Moris, Gedeon, D. 13, 17, 20

Morris, zie Morus

Morus, 40

Morsmouw, J., D. 48

Mossenton, Willem, D. 50

Munnickhoven, Jacob, D. 48

Mussenden, Willem, D. 49

Mussendine, (Mussendon, Mussenden), William, 38, 54, D. 49 , zie Jacobsz.

Navarrete, M. Fern. de, D. 53

Nes, Jan van, 21

Netherway(?), Jean, 49

Oijen Sr, Philip, D. 48, 51

Oijen Jr, Flip, D. 50

Oijen (Ooijen), Jacob, D. 50, 57

Oorsink, Hendrik A., 58

Osborne, Phillip, D. 43

Ousiel, Jac., D. 7

Outlaw, John, 23

Overschelde (Overschilde, Overschie), Ferdinandus van, 26, 28, 29, D. 38

Padieu, 27

Patton, Willem, D. 22

Pere, Abraham van, 12,42 , D. 18 , 21

Pere, Izaak van, 42

Phillips, John, D. 29

Pietersen, Jan, D. 57

Pietersz., Bastiaen, D. 48

Pietersz., Daniel, D. 48

Pietersz., Gillis (Gilis), 44, 54, D. 49

Pietersz. Heyn, Pieter, 7

Pike, Daniel, D. 48

Pinel, 49, 50

Poele, Willem van der, D. 48

Poelen, Daniel van der, D. 50

Pogson, John, 38

Poincy, de, 15, 16, D. 25, 26, 27, zie Lonvilliers 
Pré, De, D. 45

Reijning, Jan Erasmus, 40, 56, 57 Reyersz. Swart, Jan, 7

Rhee, Abraham Jan van, 42

Rhee, Jan van, 42

Rhee, Johan Abraham van, 42

Rhee, Pieter van, $12,18,42$, D. 19

Rhee Jr, Pieter van, 42

Rieu, Balthazar de, D. 38

Rijckwaert, Joannis, D. 48

Rimpou, Philip, D. 54, 55, 56

Rochefort, Ch. de, D. 29

Roelissen, Gerrit, D. 10

Rose, 28

Rudolphy, Gysbert, D. 34

Rumpoud, zie Rimpou

Runnels Sr, Adriaen, D. 48

Runnels Jr, Adriaen, 54, D. 53

Runnels, Arian, D. 48

Runnels, Nathaniel, D. 48

Runnels, Pieter, D. 48

Ruyter, M. A. de, 13, 15, 20, 21, $22,23,39$, D. $24,29,36$

Saelmons, Abraham, D. 50

Saelmons, Anthony, D. 50

Saint Laurent (Laurens, Lourens) Chevalier de, 26, 30, 33, 37, D. 44

Sain(t) Leon, de, D. 43

Saint Martin, de, zie Martin

Salomonsz., Abraham, D. 53

Salomonsz., Johannis, 54, 57, 58, D. 50

Salomonsz. J. S., D. 48

Sauvaget, D. 55

Scheurwater, Daniel, D. 42

Schorer, Johanna, 42

Schorer, Lucas, $43,44,45,46,47$, $48,49,50,51,52,53,54$, D. 46 , 47,50

Schouten, Pieter, 7

Schuttevaerder, zie Evertsen

Seabrooke, William, D. 41, 42, 43

Searles, Robert, 23

Seijs, Anthony, D. 48

Sijmons, Hendrik van Moddifort, D. 48

Sijmons, Moddifort, D. 48

Sijmonsz., Arent, D. 48

West-Indische Gids XXIII
Sijmonsz. Doncker, Jan 51, 52, 54, 57,58, D. $48,50,52$

Sijmonsz. Doncker Jr, Jan, D. 50 Sijmonsz. van Uytgeest, Dirck, 7

Sijmsen, Aernout, D. 48

Simons, Floris, D. 48

Simons, Geertgen, D. 10

Snouck, Jan, 10, 11, D. 13, 17, 18

Sorgeloos, A., D. 48

Stapleton, Sir William, 17, 25, 37, $39,40,41,43$

Stevens, Richard, 25

Stoakes, John, 19

Stuyvesant, Pieter, 13

Susteren, Cornelis, D. 48

Swart, 21, zie Reyersz.

Sweers, 21, 22

Sympson, John, 17, 25

Teerlinck, Bartol, D. 48

Teerlinck Jr, Joris, D. 48

Tertre, zie Du Tertre

Tesschemaeker, Warnerus, D. 48

Thomas, Martin, $14,15,16$, D. 25 , $26,29,30,32$

Thornhill, Thimotheus, 52, 53, D. 50

Toesijn, Martinus, D. 57

Toledo, F. de, 8, D. 27

Tongelou, L., D. 48

Torner, Timothius, D. 50

Tour, S. Courpon, Sieur de la, 16, D. $27,30,32$

Uijttendaele, Joos, D. 48

Uytgeest, van, zie Sijmonsz.

Valckenburch, (J), 19

Valckenburch, Marcus van, D. 8

Vandelbourgh, 26

Velde, Pieter van de, D. 18

Venant, Gilles, D. 22

Verunne, Michiel, 42

Vignon, D. 46

Vignon, Nicolaas, D. 48

Vijanen, Pieter van, D. 21

Vos, Abraham de, D. 44

Vrijberge, Willem L. van, D. 38

Walker, James, 25

Warner, Thomas (niet Charles), 8, 12, D. 25

Waterman, zie Fransen 
Weever, Alexander de, D. 50

Wever, Jan de, D. 48, 50

Wever, Joseph de, D. 51

Westerbaan, Laurens, D. 48

Weyts, Frederik, D. 50

Wheeler, Sir Charles, 25

Willemsd., Tryntgen, D. 10

Williams, Maurice, 23

Willoughby, Francis Lord, 18

Windt, Jan de, D. 40, zie Wint

Windt, Johannes de, D. 48

Winsepery (?), Jannes, D. 48

Wint, de, D. 44
Witt, Johan de, 20

Woestijne, Isaak van de, D. 48

Woestijne (Woestine), Pieter van

$\operatorname{de}(\mathbf{r}), 12,15$, D. $20,21,23$

Woestijne, Wouter van de, D. 48

York, zie Jacobus

Zéebourg, 27

Zeegers, Jan, 44

Zegers, Claes, D. 38

Zeun-Hus, zie Zevenhuysen

Zevenhuysen(?), P. van, D. 30

(Wordt vervolgd). 